\title{
Dossiê Coronavírus: A pandemia da globalização ou globalização da pandemia? Impactos espaciais da crise sanitária no sistema capitalista
}

Dossier Coronavirus: La pandémie de mondialisation ou la mondialisation pandémique? Impacts spatiaux de la crise sanitaire sur le système capitaliste Coronavirus Dossier: The globalization pandemic or pandemic globalization? Spatial impacts of the health crisis on the capitalist system Dossier de coronavirus: ¿La pandemia de globalización o la globalización pandémica? Impactos espaciales de la crisis sanitaria en el sistema capitalista

\section{André Luiz Teodoro Rodrigues, Gabriel de Paula Barbosa Landim e Jonathan Christian Dias dos Santos}

\section{(QpenEdition}

\section{Journals}

Edição electrónica

URL: http://journals.openedition.org/espacoeconomia/18217

DOI: 10.4000/espacoeconomia.18217

ISSN: 2317-7837

\section{Editora}

Núcleo de Pesquisa Espaço \& Economia

\section{Refêrencia eletrónica}

André Luiz Teodoro Rodrigues, Gabriel de Paula Barbosa Landim e Jonathan Christian Dias dos Santos, «Dossiê Coronavírus: A pandemia da globalização ou globalização da pandemia? Impactos espaciais da crise sanitária no sistema capitalista», Espaço e Economia [Online], 20 | 2020, posto online no dia 28 dezembro 2020, consultado o 29 janeiro 2021. URL: http://journals.openedition.org/ espacoeconomia/18217 ; DOI: https://doi.org/10.4000/espacoeconomia.18217

Este documento foi criado de forma automática no dia 29 janeiro 2021.

\section{(1) $(90$}

Espaço e Economia - Revista brasileira de geografia econômica est mise à disposition selon les termes de la licence Creative Commons Attribution - Pas d'Utilisation Commerciale - Partage dans les Mêmes Conditions 4.0 International. 


\title{
Dossiê Coronavírus: A pandemia da globalização ou globalização da pandemia? Impactos espaciais da crise sanitária no sistema capitalista
}

\author{
Dossier Coronavirus: La pandémie de mondialisation ou la mondialisation \\ pandémique? Impacts spatiaux de la crise sanitaire sur le système capitaliste \\ Coronavirus Dossier: The globalization pandemic or pandemic globalization? \\ Spatial impacts of the health crisis on the capitalist system \\ Dossier de coronavirus: ¿La pandemia de globalización o la globalización \\ pandémica? Impactos espaciales de la crisis sanitaria en el sistema capitalista
}

André Luiz Teodoro Rodrigues, Gabriel de Paula Barbosa Landim e Jonathan Christian Dias dos Santos

\section{Introdução}

2020 já ficou marcado pela explicitação das relações sociais e econômicas nas quais pessoas e setores produtivos se arranjam e rearranjam constantemente. Entretanto, com um grau de vulnerabilidade elevado a potências nunca antes demonstradas e nunca comprovadas. Neste sentido, o ato de ignorar as possibilidades de uma pandemia como a atual nos anos que antecederam 2020 demonstra a perspectiva econômica na qual o mundo fora delineado, colocando a saúde em uma esfera menor. $\mathrm{E}$ o fato de o vírus ter se expandido a partir da China serve de arcabouço metodológico e matriz de preconceitos para uma irreal normalidade do eurocentrismo e o rápido diagnóstico de uma luta ideológica em que o cenário se passa no campo político, enquanto que a real luta deve se passar no campo sanitário.

2 Os dispositivos globais que usam de unidades de medida como nanosegundos para avaliar algo são os mesmos que promoveram a disseminação do vírus. E, por mais 
mutante que ele possa ser, ficou evidente que países que apresentam um sistema de saúde mais abrangente (ou universal) saem na frente na garantia das vidas, bem como aqueles países que menos politizaram o atual momento, por mais difícil e oportunista que isso seja.

3 A partir de análises de pesquisadores em encontros virtuais (webinars), o evento "Dossiê Coronavírus" de Espaço e Economia: Revista Brasileira de Geografia Econômica promoveu uma ampliação das discussões sob o olhar da Geografia e as perspectivas distribuições espaciais e os seus desdobramentos sociais, econômicos, ideológicos e políticos. A busca por entendimento gerou um processo incansável de fazer ciência enquanto os fatos ainda estão em vigência. Afinal, a necessidade de resultados imediatos é latente ${ }^{1}$.

\section{O poder telúrico da COVID-19 e a sua condução pelo capital}

4 Em abril de 2015, o empresário Bill Gates, terceira pessoa mais rica do planeta ${ }^{2} \mathrm{e}$ fundador da gigante companhia norte-americana Microsoft, tinha um presságio sobre a realidade da humanidade: o próximo evento no planeta que iria matar mais de dez milhões de pessoas não seria uma guerra nuclear ou qualquer outro conflito militar, mas sim uma doença infectocontagiosa com alto potencial de propagação ${ }^{3}$. Realmente, o "apagar das luzes" de 2019 e o início de 2020 trouxeram ao mundo, tendo como epicentro cidade chinesa de Wuhan, um vírus que abalou as estruturas do sistemamundo que conhecemos. Nosso léxico foi demasiadamente ampliado, com vocábulos que não tínhamos familiaridade. As nuances que o vírus evidencia são várias, mas, sob o prisma da geografia, o processo de globalização se revelou primordial como trilha de investigação teórica capaz na análise de estatísticas tão volumosas.

Desde o início do milênio, a China vem se consolidando no cenário geopolítico, mercado financeiro, nas instituições internacionais de poder e no setor de tecnologia com bastante ímpeto. O território chinês se tornou a "fábrica do mundo". Era consideravelmente mais barato realocar a produção de transnacionais estadunidense $\mathrm{e}$ da Europa Ocidental para esse país. O "Made in China" teve a sua difusão pelo mundo simultaneamente com altas taxas de crescimento do Produto Interno Bruto. Atualmente, a China é a segunda maior economia do mundo, mas provavelmente em brevíssimo tempo ultrapassará os Estados Unidos. A China realiza relações comerciais com todo mundo e tem como um dos seus principais investimentos o projeto chamado "The New Silk Road Project" ou "Belt and Road Iniciative", que é uma rede global de infraestrutura de estradas, ferrovias, portos aéreos e marítimos projetados para conectar negócios entre a Ásia, Europa e África. Além disso, esse megaprojeto traduz a pujança política, econômica e diplomática da China nesse século. Outro importante empreendimento do Governo Chinês é a implantação e difusão da tecnologia de internet $5 \mathrm{G}$ pela empresa Huawei, causando um ambiente de tensão e beligerância entre os asiáticos e os norte-americanos ${ }^{5}$.

Harvey (1989) sinaliza que estamos vivenciando uma conjuntura hodierna: a "compressão do tempo-espaço" significou o encolhimento do mapa-múndi pelo advento das técnicas aniquilaram as distâncias. Desde a concepção do capitalismo, suas particularidades ressaltam uma aceleração dos ritmos da vida, ao mesmo tempo em que ultrapassou as barreiras espaciais de tal maneira que fez o mundo parece encolher sobre nós. Sincrônico ao evento rememorado, o desmantelamento do sistema fordistakeynesiano não suportou os rigores $\mathrm{e}$ tensionamentos do mercado. A 
desregulamentação e a descentralização da economia, postulados de uma nova agenda de incumbências e obrigações dos Estados e instituições internacionais de poder (Fundo Monetário Internacional, Organização das Nações Unidas, Federal Reserve etc.), passaram a ser fulcrais no sistema capitalista contemporâneo. 0 desenho geopolítico mundial sofreu uma verdadeira transformação, com os profundos e impactantes avanços do mercado. Tais alterações salientam a "crise histórica" que vivenciamos: Wallerstein (2003) retratou que o futuro do sistema vigente, mesmo não sendo inevitável ou sem alternativas, passa a ser gradualmente definido no decorrer dessa transição, cujo horizonte é bastante incerto.

7 Segundo a Universidade de John Hopkins ${ }^{6}$, o total de casos de Sars-CoV-2 no globo é de 76.934.266, com destaques para Estados Unidos (17.848.395), Índia (10.055.560), Brasil (7.238.600), Rússia (2.850.042), França (2.529.756). Já o número de óbitos é de 1.695.386, com protagonismo de Estados Unidos (317.684), Brasil (186.764), Índia (145.810), México (118.2020) e Itália (68.799). Todo esse montante explicitado anteriormente foi acumulado em um período de aproximadamente onze meses. O processo de globalização é compreendido por Santos (2003) como o "ápice do processo de internacionalização capitalista" e a rápida propagação dessa enfermidade pelo planeta ratifica essa constatação. Os modais de transportes, intensos fluxos de informações e as redes técnicas desempenham papel central neste contexto: num tempo exíguo, do paciente zero ${ }^{7}$ identificado na Província de Hubei, na China, passou a atingir a Serra da Saudade em Minas Gerais, classificada como a menor cidade brasileira, com apenas 781 habitantes (IBGE) e 6 casos confirmados. Uma cidade que está em uma distância de $17.668 \mathrm{~km}$ da outra, falantes de língua totalmente diferente, cultura, cotidiano, mas, ainda assim, enfrentando problemas semelhantes.

8 Um fator notório para uma análise da conjuntura econômica mundial, em especial do território chinês, é a comparação de contágio entre doenças causadas por coronavírus. Entre 2002 e 2003, a China foi acometida pela Síndrome Respiratória Aguda Grave (SarsCov) causando a morte de 774 pessoas, mas, naquele momento, a China e todo o Sudeste Asiático ainda estavam se recuperando de uma crise econômica da virada do século. Os chineses ainda não se apresentavam como uma potência econômica e financeira do globo e ainda tiveram mais esse revés em suas finanças ${ }^{8}$, restringindo sua propagação para zona de influência e a áreas limítrofes. Passados quase vinte anos, as circunstâncias são totalmente distintas, reverberando em uma contaminação em larga escala, uma pandemia, por conta do seu "know how" geopolítico e econômico no cenário mundial.

9 A datar do fim da Segunda Guerra Mundial, não houve perdas tão significativas na história recente da humanidade em um período tão curto. Supressão de vidas, instabilidades políticas e econômicas que ainda não podem ser mensuradas com fidedignidade. Porém, uma certeza temos: as relações não serão mais as mesmas em todas as esferas da sociedade, seja econômica, política, social, trabalhista, urbana e ambiental. A economia e os sistemas de produção vão entrar em uma dura e demorada tentativa de recuperação, o "remédio da austeridade" deve ser empregado pelas principais nações do mundo e receitado com veemência pelas Instituições Internacionais de Poder 9 . Segundo a Organização para a Cooperação e Desenvolvimento Econômico (OCDE), a queda do PIB mundial será de 4,5\%; entretanto, esse decréscimo será ainda mais agressivo nas nações subdesenvolvidas. Provavelmente, as relações de trabalho acarretarão uma precarização ainda maior: o home office se institucionalizará 
como uma medida efetiva para todas as carreiras e ofícios, com a afluência entre o labour e a morada, e, assim como o relógio foi o algoz do operário industrial no capitalismo industrial inglês, a internet será o opressor do trabalhador digital no capitalismo do meio técnico-cientifico informacional.

10 Projeta-se que o ambiente educacional será ressignificado, com a educação à distância ganhando cada vez mais destaque em comparação ao ensino tradicional-presencial e a ampliação da "youtuberização" do profissional da educação se tornando tão violenta a esse assalariado que, é possível, que percamos nossa identidade como educadores e sejamos denominados de instrutores, mediadores, articuladores, ou, ainda mais dramaticamente, colaboradores. Tudo isso será consubstanciado pelo caráter exacerbado do processo de mais-valia, pois, afinal, vivmeos em torno da mercadoria, subordinados a mesma, em todos os âmbitos da sociedade.

11 O "novo normal" naturalizará o narcisismo imagético do interlocutor com ele mesmo, mediante uma tela de computador, cujo microfone mudo e a ausência de imagem na webcam do aluno engendrará o rompimento das relações sociais, afetivas e difusoras entre aluno e professor. $\mathrm{O}$ setor cultural e de entretenimento possivelmente, neste contexto, terá preponderância em plataformas de transmissão de conteúdo, lives, emersão em ambientes como museus, parques, shows, peças e etc. A internet, a cada dia que passa, nos aproxima e afasta como se fosse um paradoxo sua coexistência.

A pandemia do novo coronavírus (Sars-CoV-2) deixou latente em todos os lugares do mundo não somente as disparidades territoriais, econômicas e sociais, mas também como as políticas neoliberais aceleram o processo de globalização de maneira perversa. A própria insuficiência de respostas contra a covid-19 se dá em um momento de diminuição de recursos públicos aos sistemas de saúde e de assistencialismo. O Estado deveria garantir à população mais vulnerável a subsistência para a sua reprodução social, gozando de "direitos" e mesmo que minimamente, para sobrevivência. Afinal, o grande problema da humanidade não se vincula tão somente à produção de bens, mas também envolve os mecanismos de distribuição para o usufruto ${ }^{10}$. Os índices de infecção e óbitos em países que lidaram com a enfermidade de maneira mais responsável e com um Estado mais presente são menos impactantes em comparação aos países que negligenciaram a doença ou nem sequer decretaram lockdown e medidas profiláticas.

13 Em concomitância na abordagem de mudanças econômico-produtivas do mundo capitalista, Martin (1996) ilustra que mediante as rápidas transformações da sociedade em amplitude, "não há maneira direta de determinar em que estágio do processo nos encontramos, de identificar as tendências e mudanças envolvidas e separar o fundamental do efêmero". Esse novo sistema de técnicas advindos desse novo ambiente metamorfoseia a "organização técnica, corporativa e social da produção, como também os padrões de demanda, consumo e distribuição". As vicissitudes de um modelo vigente dão lugar ao novo: reestruturação, revitalização, reformulação são palavras de grande presença no capitalismo contemporâneo. Haesbaert (2010) notabiliza o caráter de expansão em demasiado do capitalismo e da sociedade consumista no advento da globalização contemporânea, estágio nunca atingido na história da humanidade. Sua ampliação é intrínseca ao nexo do capital, "expandir-se tanto em profundidade, reordenando espaços já incorporados, quanto em extensão, incorporando constantemente novos territórios". 


\section{Coronavírus: uma face da veloz civilização contemporânea} geograficidade como condição histórica, percebe-se que as tramas do mundo são, ou podem ser desvendadas pela Geografia. Os impactos da covid-19 podem ser analisados como a lucidez, por mais que perversa, de uma sociedade segregada, e por que não, abandonada pelo Estado. Mas o fato também pode ser analisado como o esgarçamento da tênue linha de consumo, meio ambiente e sociedade. A internacionalização produziu espaços de consumo. É a versão bem-sucedida do neoliberalismo que insiste em ocultar as mazelas sociais por si criadas. Tornou-se evidente o que o empirismo já nos mostrava: o Apartheid social existe e está mais intenso e evidente como nunca. Este fenômeno é, por ventura, a reverberação da caricatura do capital elevada a potências superiores explicitadas no sistema-mundo durante os séculos da Revolução TécnicaCientífica-Informacional, ou seja, os séculos XX e XXI. atenuados ou não, na medida em que estas se tornam práticas do cotidiano dos cidadãos e, principalmente em áreas em que as estruturas físicas (não) existem. Hospitais, postos de pronto-atendimento e equipamentos se tornam mais escassos à medida que se caminha, anda de ônibus ou de barco para o interior do país. Durante o primeiro webinar "Geopolítica da pandemia e o papel do Brasil", mediado pelo professor do Programa de Pós-Graduação em Geografia da Universidade Federal Rural do Rio de Janeiro (PPGGEO-UFRRJ), Guilherme Ribeiro, foi ressaltado pelo pesquisador emérito do Centre National de la Recherche Scientifique (CNRS) e professor de pós-graduação na Universidade de São Paulo (USP), Hervé Théry, como o "carona-vírus" adentrou a um Brasil que não tem política pública que comporte tamanha morbidade. $\mathrm{O}$ território brasileiro garante a fluidez no vírus inversamente proporcional ao que os representantes do governo fazem para combatê-lo.

16 Afirma-se, portanto, que o crescimento do número de contaminados e sua distribuição espacial ocorre em escala exponencial. O professor do departamento de Geografia da Universidade Federal Rural do Rio de Janeiro (DGG/UFRRJ), Pablo Ibañez, confirma esta crítica quando cita e explica as ações geopolíticas deste e do governo e do anterior. A condição socioeconômica atua diretamente na minimização ou na expansão do vírus pelo território brasileiro. Se as metrópoles comportam indivíduos de grande visibilidade social e impacto na economia e ainda sim são os maiores focos da doença no Brasil (São Paulo é o maior exemplo disso), quando a doença migra para o interior, se torna mais invisível socialmente à medida que se torna mais letal. As pesquisas da professora titular na Escola de Artes, Ciências e Humanidades (EACH) da Universidade de São Paulo e coordenadora do grupo de pesquisa Políticas públicas, territorialidades e sociedade (IEA/USP), Neli Mello-Théry confirmam esta teoria.

Tal reflexão nos leva ao debate sobre o fim das políticas públicas. Se ainda há um sopro de esperança e vida nos corredores dos hospitais do Brasil é porque o Sistema Único de Saúde (SUS) exerce um papel importantíssimo de entidade atuante no território. 0 Neoliberalismo se aproveita de eventos fenomenológicos de crise dentro de uma crise constante desde, pelo menos os anos de 1970, para enfraquecer o poder do Estado a um papel de figurante, inversamente proporcional ao discurso imperativo do capital e sua necessidade de circulação. O que não é falso, mas não resolve as questões sociais, apenas fazem a máquina girar para acumulação flexível do capital concentrado. É a

Espaço e Economia, 20 | 2020 
precarização dos equipamentos evidenciados pela crise pandêmica pelo mundo neoliberal. Mas isso não é exclusividade brasileira.

o diretor-executivo do Centro para Democracia e Desenvolvimento (CDD), Adriano Nuvunga, relata em sua participação no webinar "Dossiê Coronavírus - Espaço $e$ Economia" (que contou com a mediação de Floriano de Oliveira, e participações de Eveline Algebaile, Gaudêncio Frigotto, professores do Programa de Pós-Graduação em Políticas Públicas e Formação Humana da Universidade do Estado do Rio de Janeiro (PPFH/UERJ), além de Dênis Castilho, professor dos cursos de graduação e pósgraduação do Instituto de Estudos Socioambientais da Universidade Federal de Goiás (IESA/UFG), que Moçambique passa pela mesma retórica do capital e sua supremacia perante o Estado. $\mathrm{O}$ coronavírus escancarou a luta de classes. É o velho normal e o ato de ignorar a pobreza, a miséria e a desigualdade social.

A volta da discussão no webinar "desigualdades e territorialidades na pandemia no Brasil" mediado pela professora do Instituto de Geografia da Universidade do Estado do Rio de Janeiro (IGEOG/UERJ), Regina Tunes, e com as participações dos professores Cláudio Zanotelli, da Universidade Federal do Espirito Santo (UFES), Tadeu Arrais, professor do Programa de Pós-Graduação em Geografia da Universidade Federal de Goiás (UFG), Eudes Leopoldo de Souza, professor Adjunto da Universidade Federal do Sul e Sudeste do Pará (FCH/IETU/UNIFESSPA), e

As vicissitudes podem ser menos aleatórias ou mais previsíveis, se é que isso pode acontecer, quando se analisam casos em outras regiões do mundo. $O$ webinar "Estado $e$ políticas sanitárias em países europeus", mediado por Eveline Algebaile (PPFH/UERJ), além de trazer um grande debate e um rico acervo de informações sobre o comportamento do vírus, trouxe principalmente elementos acerca do comportamento da sociedade e do poder público no continente Europeu. Os relatos de Roberto Montemerli, doutor em ciência política (Universidade de Milão) e funcionário do Serviço de Cartório e Estatística Municipal da Prefeitura de Abbiategrasso, sobre a Itália, de Lucas Pacheco, professor da Universidade Federal de Juiz de Fora (UFJF), sobre Portugal, de Denise Cristina Bomtempo, professora da graduação e pós-graduação em geografia Universidade Estadual do Ceará (UECE) e professora visitante da Université Paris I Panthéon Sorbonne/L'Institut de Géographie, sobre a França, e da geógrafa e pesquisadora da Universidade de Barcelona, Miriam Zaar, na Espanha, mostram os erros e acertos de países que estão levando mais a sério a geopolítica do momento, bem como a geografia do vírus e que não adotam práticas negacionistas como o Brasil.

Zaar cita Harvey (1989) e a compressão espaço-tempo para evidenciar o neoliberalismo e a globalização excludente. Como exemplo, fala sobre a China e o comércio internacional, o consumismo e a mercantilização de ativos públicos, como Saúde e Educação. É a redução dos serviços públicos, a degradação ambiental, a construção/ expansão do espaço urbano e a expansão geográfica do vírus.

\section{A disputa política no âmago da crise sanitária}

No debate "Crise pandêmica e disputa do poder no Estado brasileiro", os professores Leandro Dias de Oliveira e Guilherme Ribeiro, ambos do Programa de Pós-Graduação em Geografia da Universidade Federal Rural do Rio de Janeiro, juntamente com o professor Pedro Campos, do Programa de Pós-Graduação em História também da UFRRJ, e Glauco Bruce Rodrigues, professor do Programa de Pós-Graduação em Geografia da 
Universidade Federal Fluminense - Campos dos Goytacazes, discutem sob o olhar da economia política o Brasil contemporâneo e as reverberações do capitalismo em tempos de governos de extrema-direita. Outro ponto de forte reflexão e análise é o entendimento do atual do negacionismo não como fruto da ignorância, mas com um projeto deliberado. Para confirmar os mapas elucidativos de Hervé e Neli Théry, os debatedores constatam a face de uma doença de centro do mundo tornada epidemia de periferia. Eis a desinformação como política de governo indicando uma verdadeira necropolítica, planejada ou permissiva.

São os elementos ideológicos de tais governos de extrema direita que perpassam, a partir da noção de que se manter isolado é uma questão de privilégios - por si só, o anátema do capitalismo, onde a própria vida é um privilégio! -, o pressuposto de que os corpos estão passíveis de serem mortos nesta sociedade do cansaço. Ou seja, a viralidade do trabalho é a autoagressão ou o terrorismo e a vida são passíveis de serem mortas. No empuxo daquela positivação geral do mundo, como uma espécie de computador, tanto o homem quanto a sociedade se transformaram numa máquina de desempenho autista (HAN, 2010).

24 É inevitável uma retomada do capital e a tentativa de multiplicar-se, numa vida autonomizada descartável e enfeitiçada. Mas a grande questão é que o espaço urbano será o cenário de teatro das trevas que consumirá corpos e mentes. Sem dúvida alguma o espaço urbano será reestruturado, por mais deturpada que esta palavra pode hoje ser utilizada, caso analisado por Lencioni (1997), mas a vida talvez seja o espólio desta mudança. Novos cerceamentos dos tempos pós-modernos podem esgarçar o já totalmente deteriorado meio ambiente. A sociedade e a vida humana serão a geleia geral deste mundo capitalista finito e próximo deste dia.

O meio ambiente está inserido nesta conjuntura, bem como a economia. E a economia política está intimamente ligada a este meio (ambiente). 0 meio ambiente degradado que serve carvão mineral para entrar em combustão e converter energia é o mesmo meio ambiente degradado que usa a queima do carvão mineral para mover os carros elétricos, passando por usinas termoelétricas. A noção de meio ambiente como adversário ao desenvolvimento econômico é de uma fase da modernização, que via na indústria se torna "o motor da história humana".

Mas, mesmo que combalida e cientificamente refutada, esta ideia atinge reverberações múltiplas de representantes do negacionismo como forma de governo e, principalmente, forma de capital, afinal de contas, a sociedade moderna nunca se foi. $\mathrm{E}$ a covid-19 é o estopim biológico de causa aleatória que representa a inoperância ou a passividade criminosa de representantes da indústria farmacêutica e de laboratórios que já previam uma pandemia de algum modelo virótico, mas nada fizeram. A indústria só exerce sua soberania quando a necessidade produtiva do capital assim exige.

\section{As vulnerabilidades sociais expostas pela covid-19}

27 A crise é sistêmica. É de uma sociedade sistêmica. E na fuga da alienação, a sociedade está cada vez mais alienada às tabelas de vulnerabilidades e risco de contágio, como num ato de programar a vida e deixar a acaso das combinações binárias de um computador. E o avatar é o ser humano. Não à toa, os artigos publicados no "Dossiê coronavírus", na revista Espaço e Economia, deixam explícitos essas vulnerabilidades e as 
suas motivações, que acometem as populações e os territórios em suas múltiplas escalas.

De encontro com a ideia que expomos na primeira página do presente artigo, Castilho (2020) nos demonstra que o vírus tem consigo o gene da Globalização, isto é, ele possui implicitamente uma perversidade crua, impiedosa. A perversidade a qual o autor se refere, que compreendemos como as vulnerabilidades apontadas no parágrafo anterior, pode ser melhor compreendida e observada a partir da gama de artigos e estudos publicados no dossiê.

29 Passando por análises multiescalares, que variam desde uma problematização pela ausência de direito a uma quarentena nas periferias dos principais centros urbanos brasileiros, ocupadas em sua grande maioria por sujeitos que sobrevivem dos trabalhos de menor prestígio dentro do sistema capitalista, ou como diz Barbosa (2020, p.2) "trabalhadores e trabalhadoras em supermercados, motoristas de ônibus e vans, vendedores e vendedoras em trens, entregadores em suas bicicletas e motocicletas, atendentes em lojas e ambulantes no comércio de rua" até uma análise do impacto causado pelo vírus nos continentes africanos (MONIÉ, 2020) e asiático (SANTOS, 2020).

Todos estes trabalhos, expõem como a geopolítica do vírus tem atuado de forma explícita e particular nas diversas realidades espaciais que configuram o ordenamento territorial vigente no mundo. Deste modo, é possível compreender a globalização do vírus, que para além de evidenciar a sua territorialização, deixa visível as disparidades no interior dos espaços. Todavia, algo comum a essas leituras são a capacidade interpretativa de observação e constatação das políticas adotadas pelos Estados no que tange o combate a pandemia e principalmente ao seu impacto geoeconômico dentro desta distopia mundial (RODRIGUES, 2020).

31 Quando analisada em escala local, principalmente a ausência de uma política brasileira voltada para interpelar pela base societária, a mais afetada pela crise sanitária ocasionada pelo vírus, é possível observar não apenas um conflito federativo (AZEVEDO; RODRIGUES, 2020), mas também uma falta de gestão humana e de controle das consequências desta ingerência sobre as camadas mais pobres das sociedades. A parte ligada à elite econômica, rentista (PORTO-GONÇALVES, 2020) e exploradora da mão de obra e praticante de uma necropolítica, não viu suas economias, negócios ou lucros desmoronarem justamente por terem sido atendidas pelo governo hoje posto ao Brasil.

Passando para a escala macro, abrangendo outras partes do mundo, fica mais evidente a identidade globalizada do vírus. Duas coisas são demonstradas quando passamos para essa escala de análise e realizamos suas respectivas leituras: a maioria dos países não seguiu a fórmula negacionista brasileira e desenvolveram políticas públicas voltadas para a resolução ou suporte as todas as esferas de suas populações; e o espraiamento do vírus em todos os locais afetou primeiramente as classes mais ricas e detentora do capital, que possui uma grande capacidade de circulação entre os diferentes espaços do mundo, para depois chegar as classes mais baixas.

\section{Reflexões finais}

33 O que podemos observar a partir do ciclo de debates e do dossiê de Espaço e Economia: Revista Brasileira de Geografia Econômica é que as semelhanças da crise biológica ocasionada pelo novo coronavírus é uma recessão que se caracteriza pela sua 
velocidade e principalmente pela sua capacidade de atuação, isto é, sua distribuição, que fora reforçada justamente pelas redes tão necessárias ao mantimento dos fixos e fluxos do sistema capitalista.

Tais redes sempre existiram, mas se alteraram de forma significativa com a revolução tecnocientífica da globalização, uma vez que agora estão inseridas dentro de uma lógica de eliminação das barreiras geográficas e um melhor funcionamento do fluxo de capital entre os espaços do mundo. Todavia, estas mesmas redes também são capazes de facilitar uma homogeneização de culturas, gostos, força de trabalho, e inclusive, doenças. A covid-19 é uma prova disso.

Apesar dessa capacidade homogeneizadora, o vírus e as respostas a ele também demonstraram que os territórios ainda estão e são controlados por atores (Estados) muito bem delimitados e que possuem um alto grau de controle sobre seus domínios espaciais; todavia, essa rigidez não está associada apenas ao corpo político de um país. Ela também está associada, ou, melhor dizendo, está em constante atuação com os principais sujeitos do modelo econômico quase hegemônico no mundo. Grandes corporações e Estados, possuem atuações conjuntas, seja no sucesso do combate ao vírus, ou na forma como ele se intensificou e territorializou nos diferentes econômicos. Isto ocorre, pois, como apontamos anteriormente, essa pandemia é uma pandemia capitalista, e por ser capitalista, é uma pandemia globalizada.

Desta maneira, mediante aos acontecimentos oriundos da pandemia de Sars-CoV-2, conseguimos observar as claras diferenças econômicas, tecnológicas, políticas dos países do globo. Nações desenvolvidas, como os Estados Unidos e União Europeia, que são retratadas em filmes hollywoodianos como salvadoras da humanidade em uma possível pandemia, com seus infectologistas renomados e corajosos são, na verdade, espoliadoras de insumos profiláticos e monopolizadoras de equipamentos de proteção individual (EPI) ${ }^{11}$. A vacina se tornou o único mecanismo capaz de conter o contágio e o retorno da vida cotidiana. A covid-19 se propagou no planeta pelos aeroportos, portos e rodovias, pegou "carona" nas redes técnicas e se disseminou. Mediante as disparidades de contágio e de equipamentos de saúde, há o real temor que os países periféricos sejam os últimos a receberem os insumos médico-hospitalares e a vacina para suspensão da contaminação. Se a compreensão hegemônica é que o capital é perene e vital, a vida humana se torna supérflua e efêmera.

\section{BIBLIOGRAFIA}

BARBOSA, Jorge Luiz. Por uma quarentena de direitos para as favelas e as periferias! spaço e Economia [Online], 17 | 2020, posto online no dia 06 abril 2020, consultado o 17 outubro 2020. Disponível em: http://journals.openedition.org/espacoeconomia/10274

CASTILHO, Denis. Um vírus com DNA da globalização: o espectro da perversidade. Espaço e Economia [Online], 17 | 2020, posto online no dia 06 abril 2020, consultado o 17 outubro 2020. Disponível em: http://journals.openedition.org/espacoeconomia/10332 
HAESBAERT, Rogério. Regional Global: dilemas da região e da regionalização na geografia contemporânea. Rio de Janeiro: Bertrand Brasil, 2010.

HAN, Byung-Chul. Sociedade do cansaço. Petrópolis: Editora Vozes, 2017 [2010].

HARVEY, David. A Condição Pós-Moderna: Uma Pesquisa sobre as Origens da Mudança Cultural. 13. Edição. São Paulo: Edições Loyola, 2004 [1989].

HARVEY, David. A Condição Pós-Moderna: Uma Pesquisa sobre as Origens da Mudança Cultural. 13. Edição. São Paulo: Edições Loyola, 2004 [1989].

LENCIONI, Sandra. Restruturação: uma noção fundamental para o estudo das transformações e dinâmicas metropolitanas. Anais. Buenos Aires: Facultad de Filosofia y Letras/Universidad de Buenos Aires, 1997.

MARTIN, Ron. Teoria Econômica e Geografia Humana. In: GREGORY, Derek; MARTIN, Ron; SMITH, Graham (Orgs.). Geografia Humana: Sociedade, Espaço e Ciência Social. Rio de Janeiro: Jorge Zahar, 1996 [1994].

MONIÉ, Frédéric. A África subsaariana diante da pandemia de Coronavírus/COVID-19: difusão espacial, impactos e desafios. Espaço e Economia [Online], $18 \mid 2020$, posto online no dia 22 abril 2020, consultado o 17 outubro 2020. Disponível em: http://journals.openedition.org/ espacoeconomia/13629

PORTO-GONÇALVES, Carlos Walter. De neoliberais e de keynesianos em tempos de Coronavírus ", Espaço e Economia [Online], 18 | 2020, posto online no dia 14 abril 2020, consultado o 17 outubro 2020. Disponível em: http://journals.openedition.org/espacoeconomia/11699

RODRIGUES, Glauco Bruce. A distopia brasileira: o governo dos homens baixos. Espaço e Economia [Online], 18 | 2020, posto online no dia 20 abril 2020, consultado o 17 outubro 2020. Disponível em: journals.openedition.org/espacoeconomia/12871

RODRIGUES, Juliana Nunes; AZEVEDO, Daniel Abreu. Pandemia do Coronavírus e (des)coordenação federativa: evidências de um conflito político-territorial. Espaço e Economia [Online], 18 | 2020, posto online no dia 23 abril 2020, consultado o 17 outubro 2020. Disponível em: http://journals.openedition.org/espacoeconomia/12282

SANTOS, Jonathan Christian Dias. Ásia Central e seus desafios geoeconômicos perante o COVID-19. Espaço e Economia [Online], 18 | 2020, posto online no dia 17 abril 2020, consultado o 17 outubro 2020. Disponível em: http://journals.openedition.org/espacoeconomia/11821

SANTOS, Milton. O Dinheiro e o Território. GEOgraphia: Revistado Programa de Pós-Graduação em Geografia da Universidade Federal Fluminense. Niterói, v. 1, n. 1, 1999.

SANTOS, Milton. Por uma outra globalização: do pensamento único à consciência universal. 10 . ed. Rio de Janeiro: Record, 2003. 174 p.

WALLERSTEIN, Immanuel. "Mundialização ou Era de Transição? Uma Visão de Longo Prazo da Trajetória do Sistema-Mundo” In: CHESNAIS, F.; DUMÉNIL, G.; LÉVY, D.; WALLERSTEIN, I. Uma Nova Fase do Capitalismo? São Paulo: Xamã, 2003.

\section{NOTAS}

1. Este artigo é resultado da releitura e do debate ampliado do trabalho final da disciplina Reestruturação Espacial Contemporânea, ministrada pelo Prof. Dr. Leandro Dias de Oliveira, no âmbito do Programa de Pós-Graduação em Geografia da Universidade Federal Rural do Rio de 
Janeiro (PPGGEO-UFRRJ), ministrada de maneira remota no segundo semestre de 2020. Em meio aos desafios de tempos pandêmicos, refletir sobre o capitalismo, suas crises e reestruturações, os impactos econômicos, políticos e ambientais da covid-19 e mesmo acerca das mudanças no ensino, na pesquisa e no próprio comportamento narcísico da interlocução virtual se revelou uma grande necessidade teórico-analítica no curso da disciplina.

2. Ranking em tempo real das pessoas mais ricas do mundo pela revista Forbes. Disponível em: https://www.forbes.com/real-time-billionaires/\#4c146ce03d78. Todas os endereços eletrônicos consultados foram confirmados em 21 de dezembro de 2020.

3. Bill Gates: A próxima epidemia? Não estamos preparados. Disponível em: https:// www.youtube.com/watch?v=6Af6b_wyiwI.

4. Nova Rota da Seda na China. Disponível em: https://www.bloomberg.com/quicktake/china-ssilk-road.

5. Huawei, Trump, Bolsonaro e China: o que o Brasil tem a ganhar e perder se ceder aos EUA no 5G? Disponível em: https://www.bbc.com/portuguese/brasil-54634201.

6. Centro de Pesquisa Coronavírus: Informações sobre índices de infecção, óbitos, recuperados no planeta: https://coronavirus.jhu.edu/map.html. Dados retirados no dia 21 de dezembro de 2020 às $14: 43 \mathrm{GMT}$.

7. China identifica pessoa que pode ter sido paciente zero da Covid-19. Disponível em: https:// revistagalileu.globo.com/Ciencia/Saude/noticia/2020/03/china-identifica-pessoa-que-pode-tersido-paciente-zero-da-covid-19.html.

8. Como um vírus mortal abalou a economia asiática nos anos 2000. Disponível em: https:// www.dw.com/pt-br/como-um-v\%C3\%ADrus-mortal-abalou-a-economia-asi\%C3\%A1tica-nosanos-2000/a-52111716.

9. OCDE reduz previsão de queda do PIB global em 2020, de 6\% para 4,5\%. Disponível em: https:// www.istoedinheiro.com.br/ocde-reduz-previsao-de-queda-do-pib-global-em-2020-de-6-para-45/. 10. Bilionários do mundo têm mais riqueza do que $60 \%$ da população mundial. Disponível em: https://www.oxfam.org.br/noticias/bilionarios-do-mundo-tem-mais-riqueza-do-que-60-dapopulacao-mundial/.

11. A diplomacia paralela da compra de respiradores pelo Maranhão. Disponível em: https:// www.nexojornal.com.br/expresso/2020/04/21/A-diplomacia-paralela-da-compra-derespiradores-pelo-Maranh\%C3\%A3o.

\section{RESUMOS}

Em 2020, o mundo fora surpreendido pela pandemia de COVID-19, que além de paralisar a vida e o sistema econômico dos países, também expôs a fragilidade do sistema capitalista. Desde então, diversos campos da ciência, especialmente, a biotecnologia, tem sido explorada em busca de respostas e soluções para que a vida seja normaliza de forma imediata. Todavia, além de exigir uma resposta imediata para a solução do problema, a sociedade tem requerido outros campos da ciência para realizar uma leitura socioeconômica em que o vírus nos colocou. Desta forma, a Geografia tem exercido de forma satisfatória o seu papel de compreender os desdobramentos e o impacto desta crise sanitária e os desdobramentos sobre o território. 0 relato de evento, sobre o "Dossiê Coronavírus", organizado pela revista Espaço e Economia que abordamos nas páginas seguintes, é um exemplo deste esforço, que geógrafos de diferentes partes do país e do mundo, tem realizado para apontar os efeitos deste colapso sobre o coletivo social. 
En 2020, le monde avait été surpris par la pandémie de COVID-19, qui en plus de paralyser la vie et le système économique des pays, exposait également la fragilité du système capitaliste. Depuis lors, plusieurs domaines scientifiques, en particulier la biotechnologie, ont été explorés à la recherche de réponses et de solutions pour que la vie soit normalisée immédiatement. Cependant, en plus d'exiger une réponse immédiate à la solution du problème, la société a exigé d'autres domaines de la science pour effectuer une lecture socio-économique dans laquelle le virus nous a placés. Ainsi, la géographie a joué de manière satisfaisante son rôle dans la compréhension de l'évolution et de l'impact de cette crise sanitaire et de l'évolution du territoire. Le rapport de l'événement, sur le "dossier coronavirus", organisé par le magazine Espaço e Economia que nous couvrons dans les pages suivantes, est un exemple de cet effort, que des géographes de différentes régions du pays et du monde, ont mené pour souligner les effets de cet effondrement sur le collectif social.

In 2020, the world had been surprised by the COVID-19 pandemic, which in addition to paralyzing life and the economic system of countries, also exposed the fragility of the capitalist system. Since then, several fields of science, especially biotechnology, have been explored in search of answers and solutions so that life is normalized immediately. However, in addition to requiring an immediate response to the solution of the problem, society has required other fields of science to carry out a socio-economic reading in which the virus has placed us. Thus, geography has satisfactorily played its role in understanding the developments and impact of this health crisis and the developments on the territory. The event report, on the "coronavirus dossier", organized by the magazine Espaço e Economia that we cover in the following pages, is an example of this effort, which geographers from different parts of the country and the world, has carried out to point out the effects of this collapse on the social collective.

En 2020, el mundo fue sorprendido por la pandemia de COVID-19, que además de paralizar la vida y el sistema económico de los países, también expuso la fragilidad del sistema capitalista. Desde entonces, diversos campos de la ciencia, especialmente la biotecnología, ha sido explorada en busca de respuestas y soluciones para que la vida se normalice de forma inmediata. Sin embargo, además de exigir una respuesta inmediata para la solución del problema, la sociedad ha requerido otros campos de la ciencia para realizar una lectura socioeconómica en que el virus nos colocó. De esta forma, la geografía ha ejercido de forma satisfactoria su papel de comprender los desdoblamientos y el impacto de esta crisis sanitaria y los desdoblamientos sobre el territorio. El relato de evento, sobre el "dossier coronavirus", organizado por la revista espacio y economía que abordamos en las páginas siguientes, es un ejemplo de este esfuerzo, que geógrafos de diferentes partes del país y del mundo, ha realizado para señalar los efectos de este colapso sobre el colectivo social.

\section{ÍNDICE}

Mots-clés: Covid-19, géographie, géoéconomie, géopolitique

Palavras-chave: Covid-19, Geografia, Geoeconomia, Geopolítica.

Keywords: Covid-19, geography, Geoeconomy, geopolitics

Palabras claves: Covid-19, Geografía, Geoeconomía, Geopolítica. 


\section{AUTORES}

\section{ANDRÉ LUIZ TEODORO RODRIGUES}

Mestrando no Programa de Pós-Graduação em Geografia da Universidade Federal Rural do Rio de Janeiro (PPGGEO/UFRRJ) e membro do Laboratório de Geografia Econômica e Política (LAGEP / UFRRJ). E-mail: andre.rodrigues16@live.com

\section{GABRIEL DE PAULA BARBOSA LANDIM}

Mestrando no Programa de Pós-Graduação em Geografia da Universidade Federal Rural do Rio de Janeiro (PPGGEO/UFRRJ). E-mail: landimgabriel@hotmail.com

\section{JONATHAN CHRISTIAN DIAS DOS SANTOS}

Mestrando no Programa de Pós-Graduação em Geografia da Universidade Federal Rural do Rio de Janeiro (PPGGEO/UFRRJ) e membro Laboratório de Geografia Econômica e Política (LAGEP / UFRRJ). E-mail: Jonathan_christian95@hotmail.com. 